\title{
ORIGEM E SENTIDO DA RESPONSABILIDADE EM HEIDEGGER
}

\author{
Zeljko Loparic**
}

\begin{abstract}
SINTESE - Este trabalho aborda a questão da responsabilidade em Heidegger, começando por explicar por que o autor de Ser e tempo quase não utiliza esse termo nas suas analises do Dasein. Isso se deve ao fato, sustenta o artigo, de Heidegger ter operado a desconstrução do conceito tradicional de responsabilidade remetendo-o ao seu lugar de origem na relação do homem ao ser. Por fim, o artigo discute os diferentes sentido de responsabilidade introduzidos por Heidegger, em particular, a responsabilidade para com o sentido do ser a para com os outros seres humanos.
\end{abstract}

PALAVRAS-CHAVE - Heidegger. Responsabilidade. Desconstrução. Dasein. Diferença ontológica

\begin{abstract}
This article discusses the problem of responsibility in Heidegger. It starts by explaning why the author of Being and Time rarely uses the term "responsibility" (Verantwortung) in his analysis of Dasein. His reluctant use of the term is due, it is argued, to the deconstruction of the traditional concept of responsibility by showing that its place of origin is the relation of men to the being. Finally, the article estudies various senses of "deconstructed" responsibility established by Heidegger, in particular the responsibility for the meaning of being and for other human beings.

KEY WORDS - Heidegger. Responsibility. Deconstruction. Dasein, Ontological difference
\end{abstract}

\section{A responsabilidade e a diferença ontológica}

Heidegger se autodefine como pensador do sentido do ser. Nas suas análises dedicadas a esse assunto, o termo Verantwortung, responsabilidade, freqüente tanto na linguagem comum como na filosófica, quase não é usado. Isso não quer dizer que a problemática da responsabilidade humana não faça parte da questão heideggeriana do sentido do ser. Significa, antes, que essa problemática é desconstruída. ${ }^{1}$

\footnotetext{
* O presente estudo continua e desenvolve a problemática do meu livro Ética e finitude (1995). Em particular, retoma-se a questão do fundamento da responsabilidade em Heidegger, questão explicitada mas ainda não elaborada naquele texto.

** Professor da Universidade Estadual de Campinas (UNICAMP) e da Pontifícia Universidade Católica de São Paulo (PUCSP).

1 No passado, a presença de temas éticos na obra de Heidegger foi notada, ainda que casualmente, por vários autores, entre eles O. Pöggler e M. Müller. Recentemente, no entanto, vem surgindo uma literatura cada vez mais abundante e especializada dedicada explicitamente à dimensão ética (e não apenas política) do pensamento de Heidegger (Cf., por exemplo, Apel 1990, Moyse 1992, Gebert 1992, Hodges 1995). Eu mesmo, seguindo caminhos independentes, propus há pouco tempo uma leitura ética da obra de Heidegger no seu todo (Cf. Loparic, 1995).
}

\begin{tabular}{|l|l|l|l|l|l|}
\hline VERITAS & Porto Alegre & v. 44 & n. 1 & Março 1999 & p. 201-220 \\
\hline
\end{tabular}


Desconstruir um problema ou um fenômeno não é o mesmo que anulá-lo. Consiste antes em remetê-lo, como se fosse um sintoma, a seu lugar de origem. Todos os problemas e todos os fenômenos que caracterizam o ser humano têm a sua origem na relação ao ser. Quando desconstrói a responsabilidade tal como concebida pelo senso comum e pela metafísica, Heidegger 1) determina o lugar de origem a priori do fenômeno de responsabilidade na relação ao ser; 2) determina o seu sentido primário; 3) explicita, na ordem genética, os seus sentidos derivados; 4) de acordo com os resultados dessa explicitação, rediscute os diferentes sentidos corriqueiros da moralidade. Em Heidegger, não encontramos apenas uma conceituação a priori das condições de possibilidade da responsabilidade, encontramos ainda os primeiros passos na direção de uma "teoria" das responsabilidades. ${ }^{2}$

Como em geral, também no caso da desconstrução do conceito de responsabilidade convém considerar em separado as duas formulações do projeto heideggeriano de desconstrução dos conceitos da metafísica, a de Ser e tempo e a da segunda fase.

Em Ser e tempo, Heidegger remete a problemática da responsabilidade a um fenômeno a priori que caracteriza a relação ao ser do ser humano e só dele: o terque-ser, o Zu-sein-haben. Que é que o homem tem-que-ser na sua origem? Temque-responder pelo sentido do ser. Essa "questão" do ser não é teórica, nem prática; não é contemplativa, nem vivencial. Ela é anterior a todas essas distinções porque instaura o próprio existir humano que poderá, em seguida, passar a ter problemas dos tipos mencionados. A questão do ser possui, explicita Heidegger, o primado ao mesmo tempo ontológico e ôntico. Isto significa que ela é, simultaneamente, a priori, possibilitadora, e a posteriori, possibilitada: a existência humana concreta é a "resposta" à questão do sentido do ser "imposta" pela estrutura do existir humano. Essa interpelação constitutiva só se desenvolve, com toda a sua força, no acontecer do estar-aí do homem no espaço e no tempo originários. O homem tem que responder à presença dada no horizonte de um tempo cujo caráter principal é a finitude.

De onde advém exatamente a imposição de responder à questão do sentido do ser que constitui a concretude do existir humano? Da diferença mencionada entre o momento ontológico e ôntico do existir humano que responde pela nãoidentidade na estrutura mesma desse modo de existir. Nunca é demasiado repetir que, em Heidegger, caducam as diferenças metafísicas entre o sensivel e o suprasensivel, entre o fenômeno e a coisa si, entre a coisa ela mesma e a face desocultada da coisa, entre a figura e o fundo. Na origem, o ser tem o sentido de manifestação, sem qualquer reduplicação. Assim mesmo, o ser não é a manifestação pura e simples. Heidegger não é um fenomenalista. O ser pode e deve ser pensado sem o fundo, mas não pode ser pensado sem o não-ser. Não sendo réplica de nada, o ser tampouco é um oposto dialético do não-ser. Aqui nos defrontamos com um modo peculiar de diferença, distinta das metafísicas, e mais profunda: a diferença entre poder não-mais-ser e ainda estar-aí-no-mundo. É desse hiato tem-

2 Cf. Heidegger 1927, p. 288. Estou usando o termo "teoria" entre aspas para indicar que o modo de conceituação dos fenômenos do existir humano proposto por Heidegger difere das teorias científicometafísicas sobre o mesmo assunto. 
poral-acontecencial entre ainda-não e não-mais, constitutivo do ser humano, que se origina a urgência de o homem decidir sobre o sentido da presença como tal. A mesma distância íntima de si, esquecida no dia-a-dia, subjaz a todas as outras perguntas que possam vir a pesar sobre ele. O interesse em responder ao sentido do ser diz respeito, portanto, a uma não-identidade inquestionável, fundadora, chamada por Heidegger de "diferença ontológica". Ter que responder pelo sentido do ser significa, na origem, ter que responder a essa diferença.

Qual tem-que-ser a resposta do homem à diferença ontológica? Segundo Ser e tempo, a antecipação resoluta, angustiada e silenciosa do poder-não-mais-ser. A disposição de se abrir para o não-mais não fecha o homem para o seu mundo e 0 si mesmo. Por um lado, ela o abre para a sua liberdade: ao revelar o fato de 0 homem poder transcender todas as suas possibilidades de ser ônticas (ser assim ou assado), a resolução restitui ao homem a liberdade da escolha das mesmas. Por outro lado, graças ao poder transcender todas as possibilidades concretas, o ser humano se vê em condição de ultrapassar, ao mesmo tempo, o seu si-mesmo mundano definido como esse ou aquele que realiza essas ou aquelas possibilidades mundanas. O sentido primeiro da diferença ontológica é justamente a identidade do homem na não-identidade entre o si-mesmo mundano e o si-mesmo que só se manifesta e que só permanece como o ser-para-o-nada. A resposta autêntica a esse sentido da diferença ontológica é a responsabilidade para com a transcendência concretizada na antecipação resoluta da morte. ${ }^{3}$

Ao formular a responsabilidade humana à luz da diferença ontológica, Heidegger assenta a verdadeira base para sua tese de que o ser humano existe num modo diferente de todos os outros entes e que ele, e só ele, "existe". Essa tese é acompanhada de uma outra, a de que há distintos sentidos do ser dos entes não humanos, a instrumentalidade (Zuhandenheit) e a presentidade (Vorhandenheit). A diferença entre a existência do homem e esses dois sentidos do ser pode ser explicitada, inicialmente, dizendo que a existência humana é o único modo de ser que contém em si a exigência do seu próprio ultrapassamento, isto é, da nãoidentidade consigo mesmo. Todos os outros modos de ser caem sob o domínio da lei da identidade. Por isso, o homem e só o homem é um ente que, em si mesmo, é um outro de si-mesmo. Todos os outros entes são simplesmente idênticos a simesmos. Esse fato implica uma conseqüência teórica capital: a semântica a priori dos conceitos adequados para descrever os modos de ser do ser humano é radicalmente distinta da semântica a priori dos conceitos que servem para determinar as propriedades ontológicas de todos os outros entes. Em particular, a teoria da significação dos existenciais heideggerianos difere totalmente da doutrina kantiana da regras de uso das categorias da natureza e da liberdade.

$\mathrm{Na}$ mesma hora em que descobria os diferentes sentidos de responsabilidade e recolocava, de maneira nova, o problema de saber como se determina, na origem, a responsabilidade humana (esta não é imposta pelas leis da natureza ou da moral, mas pela exigência de dar sentido à presença), Heidegger também introduzia os diferentes sentidos do ser e, correlativamente, os distintos modos de teori-

3 Como esse tipo de identidade difere essencialmente do conceito tradicional de identidade pessoal, Heidegger evita, nas suas análises, o uso do termo "pessoa". 
zação sobre os entes. ${ }^{4}$ A obrigação baseada em leis, tradicionalmente considerada como primária, deve ser desconstruída. O lugar de origem da "ditadura" da lei não é a natureza humana, mas um determinado sentido do ser projetado pelo ser humano: o ser-presentidade. Com essa afirmação, Heidegger inicia a desconstrução das interpretações tradicionais da responsabilidade. Em particular, ele desvinculou esse problema do domínio do agir determinado por regras racionais.

Poderia parecer que uma tal desconstrução da responsabilidade, por mudar radicalmente os sentidos desse termo na linguagem cotidiana e na filosofia, não pode servir de ponto de partida para uma discussão razoável sobre a responsabilidade que tenha relevância para as relações humanas concretas. Isso é um engano. Esse engano pode ser corrigido mostrando que a responsabilidade de preservar a diferença ontológica se desdobra, por seu turno, em outras responsabilidades. De um modo geral, essas outras responsabilidades situam-se em dois niveis, um ontológico e o outro ôntico. No nível ontológico, o homem tem que cuidar dos diferentes sentidos da presença dos entes no seu todo. No nível ôntico, ele tem que ocupar-se e preocupar-se com os entes eles mesmos. O cuidado (Sorge) para com a transcendência torna-se, no nível ôntico, cuidado para com diferentes mundos-projetos que, por seu turno, nos impõem tarefas referentes aos outros seres humanos e as que dizem respeito às coisas intramundanas. Em resumo, a questão da responsabilidade bifurca, desde o início: uma linha vai em direção dos projetos a priori do sentido do ser e a outra em direção do deixar-ser os entes eles mesmos, os humanos e os intramundanos, à luz desse ou daquele sentido do ser, anteriormente projetado, e num mundo-projeto em que nos movemos.

Quais são, mais precisamente, as diferentes responsabilidades do homem que decorrem do ter-que-ser originário, isto é, da antecipação resoluta, angustiada e silenciosa do poder-não-mais-ser? Como se corresponde à diferença ontológica, à não-identidade que constitui a identidade do ser humano em oposição à identidade do instrumento ou das meras presentidades? A resposta a essas perguntas decorre da própria estrutura do ser humano que cuida da diferença ontológica. Ela dá-se em dois níveis, o ontológico e o ôntico. De início, daremos uma formulação apenas esquemática dessa resposta. Em seções posteriores, tentaremos torná-la mais precisa.

1) No nível ontológico, a responsabilidade de responder pela diferença ontológica como tal implica a tarefa de ser-o-Aí extático de todos os entes, à luz da possibilidade de não mais ser. ${ }^{5} \mathrm{O}$ homem é o ente que se distingue de todos os outros entes por ser o Aí da manifestação de todos os entes, inclusive do si mesmo (no sentido ôntico, "mundano"). A sua estrutura ontológica é o Da-sein, o sero-Aí. Agora podemos completar: o Aí, o a priori da pura manifestação de tudo e de todos, é o que temos-que-ser.

4 Creio que se pode defender uma tese mais forte ainda, a saber, que a distinção heideggeriana entre os diferentes sentidos do ser se baseia, historicamente, nos resultados da sua hermenêutica da facticidade da responsabilidade, obtidos a partir dos estudos da existência religiosa (tal como concebida pelo cristianismo originánio e a mística medieval, em particular, a de Meister Eckhart) e da praxis humana (tal como descrita por Aristóteles, na Ética a Nicômaco). Note-se que a hermenêutica heideggeriana da facticidade é uma recapitulação e, ao mesmo tempo, uma desconstrução da praxis aristotélica. Cf. Heidegger 1988/1923/, GA, 63. Sobre esse ponto, cf. ainda Loparic 1999, Introdução.

Heidegger II, falará em "chamamento do ser", vèr abaixo. 
A tarefa de ser-o-Aí se desdobra, no tempo, em diferentes projetos a priori do sentido do ser. Qualquer que seja o projeto, o ser compreendido sempre tem o sentido de fundo de presença sobre o qual os entes são desenhados. Dito de maneira mais técnica, um projeto a priori do sentido do ser tem sempre o caráter de uma "lógica produtiva", isto é, de um conjunto de diretivas para deixar-ser e se ocupar com os entes. ${ }^{6}$ Por exemplo, o projeto do sentido do ser elaborado por Kant na Crítica da razão pura é a lógica a priori do domínio do ser que é a natureza. Esse tipo de lógica oferece indicações a priori sobre como questionar e utilizar a natureza, isto é, o domínio da presentidade. De acordo com a hermenêutica do Ser e tempo, temos que discriminar entre a lógica produtiva da presentidade e dos outros sentidos do ser, a saber, da instrumentalidade e, sobretudo, da existencialidade. Assim como a nossa própria, a presença de outrem não tem o sentido nem de um objeto da natureza, nem de um utensílio. Se tratarmos os outros seres humanos como coisas ou como instrumentos, estaremos desobedecendo à instrução sobre o modo de deixar-ser os seres humanos que decorre do projeto do sentido do ser dos entes desse tipo, elaborado em Ser e tempo. Tal tratamento dos outros refletirá não somente a espécie de "lógica" que aceitamos, mas também a espécie de "pessoa" que somos. Só estaremos seguindo corretamente a "lógica" da área do seres humanos tal como explicitada por Heidegger se reconhecermos e respeitarmos a co-responsabilidade dos outros pelo chamamento da diferença ontológica, isto é, se nos relacionarmos com eles sempre também como "existências".?

Agora podemos também dizer o que a responsabilidade originária do plano ontológico não é. Ela não é o cuidado para com a preservação da vida. Ela não é concernida pelos interesses vitais (bem-estar etc.) próprios ou alheios. Ela não se define pelos interesses da razão nem, em particular, pelas leis da razão. Por fim, ela não pode ser explicada por meio de uma instância heterônoma ou força estranha.

2) Passamos agora às responsabilidades definidas no plano ôntico. Se o ser não é o ente, ele tampouco "se essencia (west) sem o ente". ${ }^{8}$ Posta no registro do ter-que-ser, essa tese pode ser reformulada da seguinte maneira: a responsabilidade para com o sentido do ser nunca se dá desvinculada da responsabilidade para com a presença dos entes no seu todo e de cada uma deles. Sendo assim, a responsabilidade para com o sentido do ser estende-se, necessariamente, a responsabilidade para com a presença concreta dos outros seres humanos e das coisas. ${ }^{9}$ Podemos distinguir entre os seguintes tipos de responsabilidades "concretas":

6 Cf. Heidegger 1927, par. 3 .

7 Em Ética e finitude, analisei alguns momentos centrais da preocupação com outros, descritos por Heidegger. Não se trata, enfatizei, da intersubjetividade capaz de dar força às normas. A solicitude, no sentido próprio, não consiste na prática de atos assistenciais ou parecidos, baseados em regras consensuais. Desenganada pelo ser-para-a-morte, a solicitude ajuda o outro a ficar transparente para si mesmo no ter-que-cuidar da diferença ontológica.

8 Cf. Heidegger GA, 9, p. 306.

9 Essa é a origem existencial precisa da responsabilidade para com "o como" (das Wie) da presença e, ao mesmo tempo, para com "o fato mesmo" (das Dass) da presença de tudo e de todos, isto é, da bifurcação da responsabilidade que será estilizada, na metafísica, como distinção estática entre a essência e a existência dos entes. Sobre a origem dessa distinção, cf. Heidegger GA, 24. 
a) Cuidar dos outros, em particular, deixar-ser os outros nas suas possibilidades ônticas. Além de termos a responsabilidade para com a transcendência dos outros, temos inevitavelmente que suportar o peso da sua concretude mundana, preocupando-nos com os membros de comunidades em que vivemos (famílias, comunidades de trabalho etc.).

b) Somos também responsáveis por sustentar, nos nossos modos de lidar com os entes, as coisas primeiras ou mais próximas, cujo seu modo de ser precede geneticamente $o$ das presentidades constitutivas do mundo objetivo.

c) A nossa responsabilidade concerne ainda às coisas que existem como presentidades, como objetos constituídos na metafísica da representação e assumidos pela ciência. Esse é o domínio em que são definidas as nossas obrigações morais e legais, tomadas no sentido da filosofia tradicional. Essa também é a área de compromissos com a elaboração e os resultados da teorização científica e filosófica.

Essas distinções são apenas esquemáticas e certamente não podem ser vistas como completas. Um brinquedo, por exemplo, assim como outras coisas dos bebês ou das crianças, não se manifestam nem cómo objetos externos, nem como instrumentos, nem mesmo como entes do mundo dos primitivos adultos. Os fetiches ou objetos mágicos dos primitivos não são nem instrumentos nem brinquedos. Os psicóticos e os místicos habitam reconhecidamente em mundos à parte. $\mathrm{O}$ mesmo vale para os amantes. Heidegger não diz nada sobra a nossa responsabilidade para com esses mundos. Uma coisa no entanto parece certa: o homem moderno age de maneira irresponsável, no sentido "desconstruído" desse termo, quando trata os mundos diferentes do mundo das objetidades científicas como ilusões infantis ou enganos da mentalidade primitiva a serem extirpados pela educação (ou colonização). ${ }^{10}$

Resumindo, a responsabilidade para com a diferença ontológica estende-se forçosamente a outras responsabilidades dispostas em dois planos, o ontológico e o ôntico. No plano ontológico, ela assume o sentido de ter-que-ser-o-Aí dos entes no seu todo. Essa urgência originária desdobra-se, no acontecer do ser-0-Aí, em diferentes projetos do sentido de ser, os principais sendo a existencialidade, a instrumentalidade e a presentidade. Desses projetos decorrem as diretivas a prion para deixar-ser e para ocupar-se das coisas e com os outros seres humanos. No plano ôntico, as responsabilidades inscrevem-se nos "horizontes" ontológicos abertos por esses projetos e seguem as diretivas recebidas. O horizonte da existencialidade impõe-nos a tarefa de ter-que-se preocupar com o estar-aí-no-mundo dos outros; o da instrumentalidade nos impõe o ter-que-trabalhar, finalmente, o da presentidade nos obriga a ter-que-considerar os entes como objetos meramente presentes. Esses três modos básicos de cuidado para com os entes, impostos e instruídos pelos diferentes sentidos do ser, só serão autênticos se assumidos à luz da diferença ontológica, isto é, à luz do não-ser. ${ }^{11}$

10 Sobre o status à parte do fetiche em Ser e tempo, cf. Loparic, 1996.

11 Tugendhat (1979) não viu essa multiplicidade de responsabilidade em Heidegger, porque não conseguiu entender a diferença entre os diferentes modos de ser do ente, a presentidade, a instrumentalidade e a existência. Um outra razão decisiva é a sua insistência sobre o conceito de verdade 
Na segunda fase do seu pensamento, Heidegger muda o conceito de diferença ontológica e com ele o da responsabilidade originária. Em Heidegger II, a diferença ontológica não é mais definida em termos do ser humano para o não-ser, mas como o auto-ocultamento da sublevação da presença do ente no seu todo contra o nada. Agora, a diferença ontológica não decorre mais do poder não-maisser do ser humano, mas designa o retraimento do próprio movimento doador da presença. O horizonte originário dessa doação e da sua acontecência, depositada e esquecida na história da metafísica, não é mais o Aí extático e finito, mas o tempo-espaço do quadridimensional, também finito, em que o ser é destinado ao homem para ser correspondido. Com efeito, a responsabilidade "ontológica" básica imposta dessa maneira não é a de ter-que-ser o Aí extático responsável pelo deixar-ser ontológico de tudo e de todos, mas a de se deixar usar por aquilo que inteira (ereignet) o ser-presença doada ao tempo e lhe assegura o acontecer. A responsabilidade "ôntica" do homem, por sua vez, não consiste mais em ter-quecuidar dos entes encontrados nesse ou naquele mundo-projeto, mas em ter-quedeixar os entes serem "verdadeiras" coisas num mundo-quadrindade (das Geviert). ${ }^{12}$

De novo, poderia parecer que a desconstrução da responsabilidade segundo as linhas do pensamento de Heidegger II, por mudar o uso de palavras na linguagem cotidiana e na filosofia, beirando a mística, não pudesse servir de ponto de referência para uma discussão satisfatória sobre a responsabilidade que tenha relevância para as relações humanas concretas. Isso não procede. Esse engano pode ser corrigido mostrando que a responsabilidade de preservar a diferença ontológica se desdobra, por seu turno, em outras responsabilidades, em virtude da estrutura do espaço-tempo da quadrindade que o ser humano é chamado a habitar. Trataremos de mostrar isso em seguida a partir de estudo de alguns exemplos (seção 7).

\section{A facticidade da responsabilidade e a voz da consciência responsabilizadora em Heidegger I}

A responsabilidade humana originária não decorre de um ideal. No sentido primeiro, o homem não existe como "um projeto flutuante" de uma mente, mas como "o Faktum, o fato/feito do ente que ele é, que já tem sido e permanece respondendo pelo existir". O homem, diz Heidegger, é um ente que tem que ser ( $z u$ sein hat) tal como é e tal como pode ser (wie es ist und sein hat). ${ }^{13}$

preso aos enunciados e a sua incapacidade de dar conta da verdade da diferença ontológica. A tese da diferença ontológica não pode ser fundada em nenhum "estado de coisas". Ela tem status parecido ao da verdade transcendental de Kant, verdade que possibilita outras verdades. Mas em Kant, a verdade transcendental ainda pode ser expressa em proposições (principios do entendimento) objetivamente verdadeiras. Em Heidegger, a verdade da diferença ontológica não é expressável por meio de uma proposição "objetivamente" válida. O seu desocultamento pode ser dito, sim, mas não na forma de verbalização tal como concebida pela filosofia da linguagem tradicional. Para uma discussão crítica da recepção tugendhatiana da desconstrução da ética metafísica operada por Heidegger, cf. Loparic, 1998c. Cf. Heidegger 1927, p. 176. 
Esse fato da responsabilidade pelo existir (ter-que-ser o que tem-que-ser) não é um destino imposto pela criação divina. Ele não é efeito de causa alguma e sim um Faktum que decorre de um lance (Wurf). Pelo lance, ao ser-o-Aí é transferido um poder-ser a título de responsabilidade para com o sentido do ser. A facticidade da responsabilidade tampouco não tem o caráter de um factum brutum, de uma mera presentidade (etwas Vorhandenes). A expressão heideggeriana Faktizität der Überantwortung significa que o existir humano é, sim, a corporificação ou a concretização, mas não a naturalização ou a efetivação causal, da responsabilidade transmitida ao homem pelo lance, a partir da diferença ontológica.

Se a responsabilidade é um tal fato/feito, como ela é dada ao homem? Primeiro, como não é dada. O fato/feito do lance, o ter que ser-o-Aí não pode manifestar-se, originariamente, numa representação (ibid., p. 135) nem em qualquer ato intencional do tipo husserliano. O ter-que-ser não é um "noema", nem um "tema". Qual é então o nosso acesso ao ter-que-ser? O envolvimento disposicional. A título de quê? A título de uma carga, de um ônus (Last). O ser é um peso a suportar. Este peso, revelado na disposição, é o ter-que-ser responsável pelo sentido do ser, desdobrado, em seguida, como ocupação preocupada.

Esse envolvimento bifurcado tem dois modos: o cotidiano e o próprio. O modo cotidiano é a fuga da responsabilidade transmitida. De início, o ser-o-Aí rechaça (abdrängt), evita o fato/feito da responsabilidade. O movimento dessa fuga constitui o essencial do fenômeno da queda na cotidianidade. Em particular, possibilita fenômenos "emocionais" tais como o medo. Por isso, no mais freqüente, a nossa disposição afetiva tem o caráter de indisposição (Verstimmung). No entanto, através justamente do mau humor, chegamos ao insight positivo de que somos um a-ser-no-mundo, com outros, junto das coisas. Dessa maneira, manifesta-se também a abertura ao mundo do ser humano, o seu remetimento ( $A n$ gewiesenheit) para o mundo. Aqui, o mundo deve ser entendido como concretização do Aí que o ser humano é desde sempre e a cada vez, e que possibilita o seu encontro com o ente intramundano e o ente humano.

$\mathrm{O}$ fato da responsabilidade pode também ser dado de modo próprio. O modo próprio de dadidade é a consciência responsabilizadora (das Gewissen). Mais precisamente, o fato da responsabilidade é idêntico ao Faktum da consciência responsabilizadora. Essa consciência é o ter-que-ser, a responsabilidade delegada como tal. Gostaria de seguir Heidegger mais de perto nas suas análises dedicadas a esse fenômeno.

De quem é a voz dessa consciência? A voz é do si-mesmo próprio, constituído pela possibilidade de não mais estar-aí, isto é, pela diferença ontológica. A quem se dirige a voz da consciência que responsabiliza? Ao si-mesmo mundano, cotidiano, esquecido da diferença. Como fala essa voz? O seu dizer não é verbal, pois tem o caráter de um golpe (Stoss) ou pancada (Einschlag). Nem por isso, ela é manifestação de um poder estranho ao existir humano ou de qualquer heteronomia. 
O que diz a voz da consciência falando dessa maneira não verbal? Que o homem tem que assumir a responsabilidade delegada de existir como fundamento nulo. Que significa isso? Em primeiro lugar, que o si-mesmo próprio tem que assumir o peso, transferido pelo lance, de ter a responsabilidade pelo deixar-ser a priori de tudo e de todos, inclusive de si mesmo, sem poder apoiar esse deixar-ser em fundamento algum. Em segundo lugar, o si-mesmo próprio tem que assumir o peso de também não-deixar-ser, isto é, de ser o fundamento de negatividades. Como projeto lançado, o ser-o-Aí, cada vez que escolhe certas possibilidades, deixa de escolher outras. Ele é, por isso, um projeto ao mesmo tempo fundador e nadificador, em resumo, fundamento nulo, não fundado, de presença e de ausência de todas as coisas e de todos. Em termos kantianos, o ser-o-Aí é a condição de possibilidade infundada do estar-no-mundo que, por seu turno, possibilita e simultaneamente impossibilita a concretização dos modos de ser fatuais.

A imposição de ser fundamento infundado deve ser desligada do dever (Sollen) baseado em lei (Gesetz). Nesse contexto, a culpa/dívida é ainda definida relativamente à falta de algo meramente presente que deve e pode ser. A falta significa não presença, no sentido de mera presentidade, de algo devido quer moral quer legalmente. Na sua origem, o existir humano não pode dever nada nesse sentido, não por ser perfeito, mas porque o dever/culpa revelado pela voz da consciência como "predicado" essencial do eu sou não diz respeito a privações da presentidade. Ser culpado/devedor não significa, originalmente, ofender aos interesses ou direitos dos outros e, sim, estar-com outros de modo a "ameaçar, confundir ou mesmo quebrar a sua existência" (meus grifos). Trata-se de uma negatividade originária, de um não no eu sou que gera um não no ser dos outros, diferente da falta relativa a uma exigência que diz respeito a alguma presentidade objetiva. Tal ser culpado/devedor é possível sem qualquer infração das regras "públicas" ou ideais universais.

Note-se que a voz da consciência não repreende nem critica. Esses sentidos pertencem à voz da consciência tal como entendida no cotidiano. Também são só do cotidiano e não da dimensão da transcendência os seguintes dois sentidos de culpado/devedor: 1) ter culpa/dívida para com outros relativamente a um ente que é objeto de ocupação comum, tal como objeto subtraído, emprestado, retido, tomado, roubado. Quando definido no domínio da ocupação, o conceito de culpa/dívida reduz-se ao cálculo de igualização de prejuízos; 2) ter culpa/dívida por causar um dano ao outro ser humano. Esses dois sentidos, que podem ser unificados sob a rubrica de direitos feridos, são fenômenos positivos derivados da responsabilidade originária e só fazem sentido nos domínios da instrumentalidade e da presentidade, respectivamente.

Em que consiste ouvir a voz que fala da culpa/dívida? Em deixar-se atingir por ela. Só é atingido (getroffen) pela voz quem quer (will) ser resgatado do envolvimento disposicional com o mundo. Para não haver engano, cabe ressaltar que querer ter consciência de responsabilidade não é uma atitude voluntarista no sentido comum ou filosófico da palavra. Em Ser e tempo, a vontade é um fenômeno derivado do cuidado para com o próprio ser, e não um existencial primário. 
Querer ouvir a voz significa, na origem, abrir-se, dispor-se a cuidar do ser, antes da constituição da oposição, secundária, entre ser ativo e ser passivo. A voz nos "abre", diz Heidegger, para o nosso poder sermos-o-Aí e, assim, fundamento da presença ou ausência de tudo e de todos. Só recebe a voz quem escolhe, quem "se decide" por esse poder-ser a partir do seu ser si-mesmo próprio. A dadidade do ter-que-ser tem sempre, portanto, o caráter de uma mudança existencial, não de um estado mental. Trata-se do movimento de retorno a si-mesmo, de um reatamento consigo mesmo. A voz é ouvida, na origem, como modificação do modo de existir, não de um ato de representar.

Aqui convém fazer uma parada e lançar o nosso olhar para trás, a fim de tentar avaliar a distância que separa a posição alcançada por Heidegger da metafísica tradicional. O conceito heideggeriano de ter-que-ser fatual afigura-se desconstrução existencial-ontológica, típica da primeira fase de Heidegger, do conceito metafísico do dever. Já em 1919, no mais antigo curso seu que ficou conservado, Heidegger afirma, contra a tentativa de Rickert de desligar o "valer" do "ser", que a dadidade originária da filosofia é a "dadidade do dever" (Sollensgegebenheit). Nesse ponto, Heidegger não dialoga tanto com o senso comum nem mesmo com a moral empirista e sim com Kant e os neokantianos. O ter-que-ser heideggeriano é uma desconstrução do ter-que-obedecer à lei moral no sentido de Kant. Já em Kant o dever não é constituído pelas considerações quanto à sobrevivência ou ao bem-estar pessoal, nem quanto aos interesses dos outros, nem por qualquer outra consideração de conteúdo material ou afetivo (valorativo), mas única e exclusivamente pelo comando da razão, pelo seu sic volo, sic íubeo. A ditadura da razão não determina qualquer agir em particular (por exemplo, preservar a vida ou otimizar certos parâmetros empíricos da convivência entre os homens), mas tão somente a forma, o como do agir e da vida no seu todo, tanto dos indivíduos como do gênero humano. Estamos na esfera da determinação não apenas formal mas também pura do existir dos homens, distinta do domínio comandado pelo consenso social e pelas exigências ligadas à prestação de serviços do bem-estar. ${ }^{14}$ Em Kant, a vida moral resulta do fato da razão, da coerção ( $Z$ wang) da vontade finita humana pela lei moral. Em Heidegger, o estar-no-mundo próprio é fruto do fato da responsabilidade para com a presença como tal e para com todos os presentes, transmitida (überantwortet) ao homem pela não-identidade consigo mesmo, cisão reveladora da diferença ontológica entre o ainda-sim e não-mais. Em nenhum dos casos, trata-se de fato bruto, de uma dadidade que pertencesse ao domínio dos fenômenos naturais, a ser concebida à luz da categoria da efetividade. Em Kant, o fato da razão, o sentimento de respeito pela lei moral, a necessitação (Nötigung) proveniente dessa mesma lei, assinalarão um modo de existir (Dasein) que pertence ao mundo das coisas noumenais. Em Heidegger, onde não há mais a distinção entre fenômenos e coisa em si, a facticidade da responsabilidade transferida será distinguida de modos de ser intramundanos pela afirmação do sentido próprio da presença do Dasein humano: o de ter-que-ser o Aí de todas as coisas.

14 Para uma interpretaçấo detalhada da semântica kantiana da lei moral, cf. Loparic, 1998b. 


\section{Exemplos ônticos da facticidade da responsabilidade: a vida religiosa no sentido de cristianismo primitivo e o Édipo de Sófocles}

Se quiséssemos especificar um modelo ôntico para o ter-que-ser heideggeriano, poderíamos escolher, seguindo Heidegger, o Édipo de Sófocles. Mostrei, num outro texto, ${ }^{15}$ que um exemplo concreto de uma vida dominada pela questão do sentido do ser é, com efeito, o herói trágico grego. Édipo, em particular, é confrontado pela pergunta da esfinge que pode ser reformulada da seguinte maneira: Quem é o homem? Essa pergunta leva imediatamente a uma outra: De onde vem o homem? A tragédia de Sófocles mostra que Édipo se engana quando, depois de responder à pergunta da esfinge, conclui que sabe quem é o homem e, portanto, quem é ele mesmo. O seu destino posterior ensina-lhe que ele desconhecia uma e outra coisa. A pergunta da esfinge só fica respondida verdadeiramente quando Édipo constata que tem-que-viver sem pai e sem mãe, isto é, sem as origens ônticas, como um ser mortal definido apenas pela diferença temível entre o ser e o não-ser. A aceitação da culpa por parte de Édipo, a admissão do crime de ter perturbado a boa ordem das gerações por ter-se tornado marido da sua mãe $e$ irmão dos seus filhos, a submissão desse "homem extraordinário" à condenação ao exílio nas montanhas de Citerão, onde esperará a morte, privado do convívio dos cidadãos comuns, equivale, na linguagem poética de Sófocles, ao que Heidegger denomina "vontade de ter consciência". Ele aceita o que é dito pela voz da consciência responsabilizadora: que a "verdade" do homem é a diferença ontológica, a negatividade que não permite ao ser humano possuir uma identidade definida, quer por uma essência estática, quer por uma seqüência linear, temporalcausal. O mito de Édipo recontado por Sófocles apresenta - essa é a interpretação que proponho - um caso ôntico da aceitação da responsabilidade para com a diferença ontológica como tal. ${ }^{16}$ De acordo com as preleções de Heidegger de 1919, certos modos de vida religiosa (Heidegger tem em vista a vida dos primeiros cristãos e a dos místicos medievais) e artística também podem exemplificar a tese de que o fato da responsabilidade (Sollensgegebenheit) pode valer como a "objetividade originária". ${ }^{17}$

É fácil ver por que a questăo de Hamlet: to be or not to be? não serve, como sugerem alguns, como questão-guia dos problemas "práticos" em geral. ${ }^{18} \mathrm{~A}$ pergunta do herói shakespeariano pode ser reformulada como: é melhor ser ou não ser? Tal indagação não ajuda a entender a problemática da práxis humana focalizada por Heidegger. Em Ser e tempo, não se trata, em primeiro lugar, do problema de determinar o "valor" da vida, nem as possibilidades práticas da ação preserva-

15 Cf. Loparic 1990, cap. 6.

16 A presente interpretação de Édipo de Sófocles difere essencialmente da oferecida pela psicanálise freudiana. Para maiores detalhes, Cf. Loparic, 1990, cap. VI.6.

17 De importância capital para esse ponto são as primeiras preleçōes preservadas de Heidegger, oferecidas no início de 1919 (cf. GA, 56/57).

18 Foi Tugendhat quem tomou a questão de Hamlet como um fio condutor para entender a temática do sentido do ser em Heidegger (Cf. Tugendhat 1979, p. 36, 177, 235). 
dora e favorecedora da vida. O ter-que-ser não é o sinônimo do ter-que-agir. Não obstante, trata-se, sim, de um atuar (handeln), aquele atuar no qual se decide 0 que significa ser, antes mesmo de decidir se vou ser ou não, e se vou ser dessa ou daquela maneira concreta. ${ }^{19}$ Hamlet não se dirige ao problema metafísico: que é o ente? Hamlet cuida, pelo menos na interpretação comum, de decidir se a vida vale a pena à luz da sua biografia, não à luz da diferença ontológica. Ele não se dirige à pergunta heideggeriana do sentido do existir em nenhuma das suas formas e não pode, portanto, constituir-se no exemplo-guia para entender a problemática heideggeriana. ${ }^{20}$

\section{Um exemplo ôntico da responsabilidade para com os outros: responsabilidade das mães para com os seus bebês}

Recentemente, Frederick A. Olafson dedicou um estudo detalhado à questão da fundamentação da ética da responsabilidade para com outros no estar-com heideggeriano. O seu argumento básico é o seguinte: como contribuímos decisivamente para a constituição dos outros em virtude do tipo de entes que somos, não podemos repudiar os outros, quer explicita quer implicitamente, sem uma incoerência grave. ${ }^{21}$ Charles Guignon desenvolveu a tese de que o si-mesmo heideggeriano pode ser interpretado como um agente moral e que a explicitação heideggeriana da vida humana oferece pontos de vista inovadores sobre as questões morais de base. Em particular, a teoria heideggeriana do estar-com ofereceria uma alternativa à postura da psicanálise tradicional sobre a natureza humana e a prática clínica. ${ }^{22}$

Concordo inteiramente com essas teses. No que segue, apresentarei um material empírico, provindo da psicanálise mais recente, para exemplificar as intuições básicas de Olafson e Guignon. Poder-se-ia afirmar, seguindo o modo de pensar tradicional, que, desde o ponto de vista moral, os cuidados maternos dizem respeito exclusivamente aos problemas de sobrevivência e do bem-estar do bebê (e secundariamente, da mãe). Tal ponto de vista é plausível, mas colide com evidências fatuais. Segundo D. W. Winnicott, um dos psicanalistas mais influentes depois de Freud, a relação das mães com seus bebês não pode ser definida apenas, nem mesmo principalmente, em termos dos cuidados para com a sobrevivência e o bem-estar. O bebê, na relação com a mãe, não busca, em primeiro lugar, a alimentação e o prazer. Ele busca, antes disso e sobretudo, um colo, isto é, um lugar em que possa repousar ou ficar agitado e, assim, existir. Para o bebê, a mãe

19 Em Heidegger, o próprio pensar é chamado de handeln, atuar fundamental para o qual o homem é convocado pelo próprio ser. Prefiro o termo "atuar" ao "agir", que tem uma conotação pragmática muito pronunciada.

20 Winnicott tem uma interpretação própria da questão de Hamlet, que aproxima o impasse desse herói do ser-o-Aí heideggeriano. Segundo o psicanalista inglês, Hamlet está-se debatendo entre permanecer na condição de ser quem sempre já era ou se decide agir, isto é, matar o padrasto, cf. Winnicott 1971, cap. 5.

22

Cf. Gignon 1993, p. 216 e 231. 
primária não é uma outra pessoa, nem um objeto de um modo geral, e sim o ambiente, o espaço-tempo-cuidado que o acolhe. Quando o bebê se assenta no seu primeiro mundo, ele não o faz para tratar dos "problemas da vida boa" e sim, para começar e para continuar a existir, para morar e demorar-se no mundo. Em virtude da tendência inata à integração que define a natureza do bebê humano, o seu problema principal é a "continuidade do ser", problema que só poderá ser resolvido se o bebê se integrar com a mãe-ambiente, entrando com ela na relação de "dependência absoluta". Todos os outros problemas são derivados dessa urgência inicial de existir. Por conseguinte, a mãe deve ser vista como responsável, em primeiro lugar, em facilitar ao seu bebê a resolução, graças à espontaneidade e à criatividade que também o caraterizam, exatamente desse problema de continuidade de ser.

Caso ela falhe nessa incumbência, o processo de amadurecimento do bebê será interrompido, ele terá que reagir ao invés de progredir e poderá tornar-se, em virtude disso, um doente psíquico. Nem a mãe nem ninguém estão em condições de dizer, verbalizando, em que e quando exatamente a mãe falha. Uma mãe pode fracassar, por exemplo, porque é depressiva. No entanto, não há regras baseadàs na razão para distinguir entre a mãe depressiva e a suficientemente boa. Isso vale em geral: não há critérios racionais gerais para julgar as falhas da mãe; apenas indicações genéricas sobre a natureza humana e o amadurecimento humano, isto é, sobre a acontecencialidade constitutiva do ser humano.

Tampouco há critérios que garantam às mães serem bem sucedidas: de novo, só há indicações genéricas, baseadas não no saber objetivante da razão teórica ou prática mas no bom senso. Sobre esse ponto Winnicott é taxativo: as mães não se devem deixar guiar por nenhum conjunto de regras científicas (enunciados veritativos) ou práticas (enunciados valorativos ou regras do agir). A linguagem objetivante do discurso científico e moral dos adultos não se aplica à intimidade entre a mãe e o bebê. As mães tampouco precisam desse tipo de conhecimento. Elas sabem o que fazer naturalmente, por um saber pré-racional e pré-verbal, típico das mulheres regredidas à "preocupação materna primária", um saber que funciona bem há centenas de milhares de anos e que não admite ser esclarecido, confirmado ou corrigido, pelo consenso entre os peritos. ${ }^{23}$

A mãe winnicottiana tem, sim, um problema de ter-que-ser, a saber, o ter que ser mãe suficientemente boa e, assim, facilitar o amadurecimento do bebê. Mas o conceito de bem, adequado para caraterizar essa bondade, não pode ser definido por formação de consensos intersubjetivos, em termos de regulamentação das ações. A bondade da mãe não é apenas, nem essencialmente, um problema do agir racional. A mãe é boa se é confiável, real, se estiver onde deve estar de acordo com as urgências vagas do bebê. Qualquer tentativa de impor regras a essa bondade seria o mesmo que destruí-la. Nesse domínio ainda "subjetivo", o terque-ser diz respeito a um outro ser humano que está ainda às voltas com o pro-

23 Seria interessante continuar essa linha de pensamento mostrando a relação entre a experiência de intimidade e a criatividade artística. Teríamos aqui a oportunidade de explicitar a relação especial entre a psicanálise de Winnicott e a poesia, um ponto a mais que aproxima Winnicott a Heidegger. 
blema de constituir a continuidade do seu ser. O que está em jogo nessa relação é, tão somente, a realidade de si mesmo do bebê e do seu mundo. Realidade que, dada num "senso do real" (sense of real) inicial, tem, sublinha Winnicott, um sentido totalmente diferente da realidade externa, objetivamente percebida, dada na relação sujeito-objeto, domínio de estipulações da moral racional dos adultos. Não apenas a relação inicial mãe-bebê, a vida humana no seu todo escapa, em virtude da natureza humana, a qualquer estilização em termos do agir racional com respeito a fins. ${ }^{24}$

Poder-se-ia objetar que estamos nos distanciando muito da analítica existencial de Heidegger: parece descabido comparar problemas ônticos dos bebês com a questão ontológica do ser. Essa objeção não procede. Seguindo Heidegger, o problema do sentido do ser, ontologicamente fundamental, é, ao mesmo tempo, onticamente o mais urgente. Winnicott parece ecoar essa tese ao lamentar que nem todo filósofo consegue ver que o problema do sentido da realidade não só "aflige todo ser humano" como também "constitui uma descrição do relacionamento inicial com a realidade externa no momento de primeira amamentação" ou de "qualquer primeiro contato". Os bebês que tiveram sorte, isto é, uma mãe suficientemente boa, resolveram esse problema sem terem precisado tornar-se psicóticos ou filósofos. Sobre outros, que não tiveram essa sorte, pesa permanentemente a ameaça da perda da capacidade de relacionar-se com o real. Para eles, o problema da realidade "torna-se e permanece vital, uma questão de vida ou morte". ${ }^{25}$ Por outro lado, o próprio Heidegger reconhece, em Ser e tempo, que privilegiou as análises do ser-para-o-fim (Sein zum Ende), e deu pouca atenção ao serpara-o-início (Sein zum Anfang) e que, por essa razão, a sua analítica pode ser considerada "unilateral", ${ }^{26}$ Ele de fato não disse nada, em 1927, sobre o estar-com que carateriza as relações mães-bebês. No entanto, alguns dos textos que escreveu ao longo da sua obra parecem dialogar com as análises detalhadas da psicanálise winnicottiana. Nas preleções de 1928/29, Heidegger deixou claro que o Dasein infantil é um deixar ser dos entes, essencialmente acontecencial e sensivel aos distúrbios. Desde o primeiro dia da vida terrestre, o bebê humano tem que se defender como pode dos choques que vem recebendo para, em seguida, aprender a evitá-los e mesmo a enfrentá-los ativamente. Os primeiros "fenômenos intencionais" têm como tarefa, diz Heidegger, "elaborar a primeira situação na qual se encontra o Dasein infantil inicialmente entregue ao mundo sem amparo".27

Bem mais tarde, já nos anos 60 , nos seminários com o psicanalista suíço Medard Boss, Heidegger falará repetidas vezes do amparo dado aos bebês pelas mães. O ser humano é essencialmente "necessitado de ajuda" (hilfsbedürftig),

24 Winnicott poderia ser usado, ainda, para ilustrar o problema moral da relaçăo bebê-mãe. Aqui de novo a responsabilidade não pode ainda ser definida em termos de ações dirigidas para fins. Esse estudo ofereceria boa oportunidade para se deter sobre o problema de periculosidade da moral objetivante, assunto já abordado com força e propriedade por Nietzsche. Sobre esse último ponto, cf. Loparic, 1990, cap. VIII.

25

Cf. Heidegger, 1927, p. 373.

Cf. Heidegger, 1928/29, par. 16. 
"porque está sempre em perigo de se perder e de não dar conta de si mesmo". ${ }^{28}$ No caso dos bebês e das crianças, essa necessidade se mostra como entrega ao modo de ser da mãe. Dessa maneira, e aparentemente só dessa maneira, o ser humano pode constituir a continuidade e a estabilidade do seu si-mesmo (das Selbstsein) e a do seu mundo. As angústias de descontinuidade dependem, todas elas, da "proteção da mãe" (die Geborgenheit bei der Mutter), "que é um estarcom determinado, não uma unidade formal". ${ }^{29}$ Essa última observação é decisiva: eḷa mostra que Heidegger distinguia claramente entre a responsabilidade para com outros definida no nível da estrutura mesma do existir humano e as responsabilidades concretas para com outros concretos, exemplificadas, no caso, pela responsabilidade da mãe de "proteger" a continuidade e a estabilidade do ser e do mundo do seu bebê. Nas recordações da infância contidas em Der Feldweg (1949), encontramos acenado o sentido dessa proteção materna. Heidegger lembra as viagens pelo mundo feitas em navios de suas brincadeiras de criança. Eram aventuras que sempre reencontravam o caminho de volta à terra firme e ainda não sabiam nada das andanças que deixam para trás tọdos os pontos fixos. O caráter onírico dessas viagens iniciais "permaneceu oculto num esplendor quase imperceptivel, que repousava sobre todas as coisas". Em parte, pelo menos, porque a mãe estava lá. O seu "olhar" e a sua "mão" delimitavam o domínio dessas primeiras travessias: "Era como se o seu cuidado não verbalizado (ungesprochene Sorge) protegesse todos os seres (alles Wesen)". ${ }^{30}$

Creio que as teses conhecidas de Winnicott sobre a preocupação materna primária ilustram bem a existência de uma área das relações humanas na qual as regras do agir racional com respeito a fins não fazem sentido. Se cotejadas com os textos mencionados de Heidegger, creio que oferecem mais um exemplo das teses heideggerianas: 1) de que a responsabilidade humana se diz em vários sentidos; 2) de que ela não diz respeito, inicial e primordialmente, à racionalidade do agir mas ao sentido do ser do si-mesmo a ser continuado e do mundo originário a ser habitado; 3) de que essa responsabilidade, na origem, não pode nem mesmo deve ser arregimentada pelas regras da razão definidas no domínio de objetos compartilhados e objetivamente percebidos. ${ }^{31}$

\footnotetext{
28 Cf. Heidegger, 1987, p. 202.

29 lbid., p. 256.

30 Cf. Heidegger, 1946, GA, 13, p. 88.

31 A partir de Winnicott poderiam ser discutidas várias outras criticas de Tugendhat a Heidegger, por exemplo a de que ser é fazer e a de que o conceito do si-mesmo é mal construído. Na psicanálise winnicottiana, o poder ser é mais original e essencialmente diferente do que o poder fazer e a constituição do si-mesmo, que não é sinônimo da pessoa inteira, é a tarefa inicial mais importante do processo de amadurecimento. Tugendhat, ao criticar Heidegger nesses dois pontos, não somente ficou preso a pontos de vista filosóficos que entraram em crise como também demonstrou não estar acompanhando o desenvolvimento das ciências empíricas dos nossos dias.
} 


\section{Responsabilidades prático-instrumentais e prático-teóricas}

Abrimos essa seção não para desenvolver o seu tema, mas tão somente para sublinhar a importância da nossa tese de que o conceito de responsabilidade em Heidegger tem vários sentidos interligados entre si, decorrentes da estrutura do ter-que-ser que carateriza o ser humano. Como dissemos acima, em virtude da responsabilidade para com o sentido do ser em geral, os cuidados humanos estendem-se, necessariamente, também aos domínios da instrumentalidade e ao das meras presentidades. No primeiro domínio, a responsabilidade é articulada pela reflexão prática (Überlegung). No segundo, pela razão prático-teórica. É só neste último domínio que a responsabilidade para com o ser recebe o sentido de regulamentação racional do agir. Nesse caso, a voz da consciência assume a forma da responsabilidade moral tradicional (Verantwortung). ${ }^{32}$ A mesma voz que chama para o deixar-ser originário também solicita responsabilidades derivadas, definidas pelas regras e normas públicas, preceitos que permitem que se calculem as recompensas. Tal responsabilidade é irrecusável, mas ela não é nem única nem originária. Mais uma vez, a responsabilidade no sentido original é para com o dever/culpa inerente ao ser-o-Aí, com outros, um ter-que-deixar-ser que, na hora em que se cumpre, necessariamente falha, isto é, não deixa-ser. Não se trata (ainda) de responsabilidade definida por uma lei ou norma. Na origem, o mau e o bom nada têm a ver com prescrições universalizáveis, como em Kant. Nem com regras consensuais, como, por exemplo, em Tugendhat. ${ }^{33}$ Mas para que se possa ver essa multiplicidade de sentidos da responsabilidade em Heidegger é preciso admitir que existem vários sentidos do ser e que esses sentidos determinam, tornam possível, não somente o que pode mas também o que deve ser.

\section{O chamamento do ser e a responsabilidade em segundo Heidegger}

Como vimos na primeira seção, em Heidegger II, a responsabilidade do homem não procede da diferença ontológica que impõe o ter que ser como o Aí de tudo e de todos, mas da diferença ontológica entendida como o auto-ocultamento da sublevação da presençà do ente no seu todo contra o nada, sem nenhuma referência aos modos de ser do ser humano e, em particular, ao ser-para-a-morte. A determinação fundamental do ser humano é a de ser aberto para a interpelação pela presença. Nessa determinação pelo ser está também a mais alta aspiração do homem, a sua "ética". ${ }^{34}$ Heidegger usa aspas para significar que o termo é empregado aqui no sentido desconstruído. Ser ético, no sentido originário, significa ter que ser a abertura do mundo, ter que sustentar (ausstehen) essa abertura. ${ }^{35}$ Aqui, anota Heidegger, o "ser" tem um sentido transitivo. O "objeto direto" do ser é o Aí, o espaço-tempo de manifestação de todas as coisas. "O homem é", explicita Heidegger, "na medida em que 'existe', suporta, o Aí, na medida em que

32 Cf. Heidegger, 1927, p. 288 e 294.

33 Cf. Tugendhat, 1979.

34 Cf. Heidegger, 1987, p. 273.

35 Ibid., p. 292. 
assume resguardar o Aí, isto é, a abertura dos entes, na medida em que, conjuntando-se a ela, dá-lhe forma". ${ }^{36} \mathrm{O}$ distintivo ontológico do homem é ter-quesuportar o ser-o-Aí. Nessa sua responsabilidade primeira, está também a sua liberdade originária: ser livre para a solicitação da presença sublevada contra 0 nada. 37

Esse ter-que-sustentar da abertura (Offenstängikeit) da manifestação dos entes multiplica-se em responsabilidades derivadas. O homem é referido ao que se desoculta na abertura e que, dessa maneira, o incita. Assim, o homem é exigido a corresponder (entsprechen) ao ente que se desoculta pelo seu comportamento. Essa resposta comportamental terá que tomar o ente "sob sua proteção e ajudá-lo, na medida do possivel, a se desenvolver a partir de si mesmo" (grifos nossos). ${ }^{38}$ Corresponder dessa maneira ao destinamento contencioso do ser é um ter-que (müssen) mais originário do que qualquer "dever moral".

Como vemos, em Heidegger II, o problema da origem e do sentido da responsabilidade é tratado de maneira semelhante ao de Heidegger I. Nos dois casos, a origem está na diferença ontológica e a responsabilidade primeira é para com essa diferença, multiplicando-se necessariamente em responsabilidades para com os entes no seu todo. O homem cumpre essa sua responsabilidade na medida em que aprende a morar no espaço da manifestação e, ao mesmo tempo, do ocultamento do ser. A grande novidade está na maneira como Heidegger concebe a diferença ontológica. Em Heidegger I, esta é concebida como não-identidade entre o si-mesmo que pode o não-ser e o si-mesmo que pode estar-aí-no-mundo, isto é, em termos da diferença entre as possibilidades mundanas e a possibilidade de transcender o mundo, inscritas no existir do ser humano. Em Heidegger II, a diferença é entre o ser ele mesmo e o ser dos entes no seu todo. Essa diferença aparece de duas maneiras. Primeiramente, à luz da tematização do ser como doação (Gabe) e não mais, no sentido grego, como mera presença. Em segundo lugar, à luz da história da metafísica que é o repositório das determinações do sentido do ser dos entes (idéia, enérgeia, atualidade, representidade, vontade de poder) resultantes da acontecência do ser subjacente. A diferença entre o que doa o ser e o ser doado, assim como a entre as diferentes estampas (Prägungen) do ser explicitadas na metafísica, não é mais concebida como interna à estrutura do existir humano, mas como aquilo que requisita um ente com a estrutura do ser humano.

Daí decorrem todas as diferenças no sentido das responsabilidades derivadas. Em Heidegger I, o ter-que-ser original explicita-se como um morar que tem o sentido de habitar o mundo-projeto, o lugar em que se decidem os sentidos do ser. Esse morar é, conforme mostramos, um demorar-se nas tarefas da vida comunitária cotidiana, da teorização autêntica e assim por diante. Já em Heidegger II, o ter que morar significa ter que assentar-se no mundo-quadrindade, o espaçotempo em que se joga o jogo da doação do ser. Aqui, o morar tem o sentido de abrir-se para determinadas maneiras de edificar e pensar que tem que ultrapassar o mero trabalho e, em particular, o intervencionismo técnico, instalação de tudo e

\footnotetext{
36 Ibid., p. 356.

37 Ibid., p. 272 e 274.

38 Ibid., p. 292.
} 
de todos guiada pelos cálculos do saber objetivante. Em Heidegger I, a responsabilidade fundamental para com outros é definida como ajuda a ficar transparente para si mesmo. Em Heidegger II, essa responsabilidade continua sendo a de ajudá-los a achar, pensando por conta própria, o caminho da sua essenciação. ${ }^{39}$ Mas esse caminho agora é outro: ele vai numa direção que se afasta do mundo da técnica e leva a um distanciamento da mera presentidade que Heidegger I ainda não podia caracterizar. Nos dois casos, entretanto, trata-se de favorecer nos outros a capacidade de corresponder ao chamado do ser que é o "dever" fundamental de cada um segundo a ética finitista de Heidegger. ${ }^{40}$

\section{Estudo de exemplos:}

a responsabilidade humana pelas coisas e pela linguagem

Consideremos alguns exemplos do ter-que-ser no sentido de Heidegger II. Para exemplificar a responsabilidade para com a diferença ontológica como tal, explicitarei o que Heidegger diz sobre as nossas responsabilidades para com a linguagem. ${ }^{41}$ Uma delas é a tarefa de servir de mensageiro, de arauto, do que diz a voz da dobra (Zwiefalt) do ser. Uma outra, menos extrema, é a de cuidar desse dito depositado ao longo da história nos livros, tanto nos de metafísica como nos de poesia. O ser, mediante a linguagem, nos fala monologicamente, mas a nossa resposta, porque histórica, acontecencial, é sempre dialógica. Aqui, a responsabilidade fundamental implica, portanto, o diálogo com os pensadores do passado sobre o sentido da interpelação do ser humano pelo ser, isto é, sobre as maneiras como os pensadores decisivos atenderam ao chamado da diferença. O que obriga hoje o nosso pensamento é o que foi dito pelos nossos antepassados essenciais. É deles que recebemos as "prescrições não escritas" e "tarefas" do pensar. ${ }^{42}$ É nesse sentido que Heidegger dirá que a poesia de Hölderlin se tornou o destino (Schicksal) da sua filosofia. A menção de Hölderlin no presente contexto permite constatar que, segundo Heidegger, a palavra capaz de dizer a diferença não é a palavra portadora de informações sobre estados de coisas, palavra plena de sentido objetivo, constituída de acordo com as regras da semântica que fundamentam o nosso discurso sobre as presentidades. Tampouco se trata da palavra socialmente controlável. Em Heidegger, o diálogo não tem, como em Apel ou Habermas, o sentido do debate argumentativo das assembléias livres de conflitos, dos conselhos populares consensuais ou das comissões de peritos regidos pelas normas do discurso veritativo. A palavra do diálogo da nossa primeira responsabilidade é parecida antes com a "palavra quebrada" dos poetas essenciais. ${ }^{43}$

39 Cf. Heidegger, 1959, p. 127.

40 Levinas seguirá Heidegger no seu distanciamento do infinitismo tradicional. Não o fará, no entanto, para reconhecer a precisão do tomar-chão na verdade do ser e sim a fim de preparar o homem para o sacrifício do ser. Retornando à tradição judaica, liberada com a ajuda de Heidegger da tradição metafísica infinitista, Levinas tentará elaborar uma ética também finitista, mas independente de qualquer pensamento do ser, uma ética do serviço ao próximo, traço vivo do Outro-que-o-ser. Cf. Heidegger, 1959, p. 121-122. Essa tarefa é comparada à tarefa dos poetas gregos de trazerem aos homens a mensagem dos deuses.

42 Cf. Heidegger, 1959, p. 123, 125 e 134.

43 Sobre o conceito heideggeriano de palavra quebrada, cf. Loparic, 1995, cap. 9. 
Pode causar estranheza querer exemplificar o caráter concreto da responsabilidade pela diferença ontológica acenando para a possibilidade de um diálogo entre filósofos que se valesse das virtudes de uma linguagem semelhante à dos poetas, nem sempre gramatical e certamente não de uso comum. Vista nessa perspectiva, não seria a filosofia reduzida a uma estética? Ou, pior, a um exercício verbal sem controle e, nesse sentido, irresponsável? O apontamento da intimidade entre a filosofia de Heidegger e a poesia não é, no entanto, uma desautorização do seu pensamento enquanto irresponsável ou irrelevante para a "vida real". Tratase, antes, de uma indicação de que o problema de responsabilidade descoberto por Heidegger não se reduz ao que, desde Aristóteles, chamam-se "questões práticas". Como já mostrei pelo exemplo da relação mãe-bebê, existem problemas de capital importância para a saúde, isto é, para o existir e para o amadurecimento pessoal do ser humano que só admitem soluções em termos da comunicação não verbal e não racionalizada. Essas soluções, mesmo quando postas, em seguida, na boa forma verbal, têm-que-preservar uma espontaneidade criativa que lembra, não por acaso, a infinita e lúdica variedade dos dizeres poéticos.

Para terminar, menciono uma outra a responsabilidade típica do Heidegger II, a de resguardar as coisas, que estudei em Ética e finitude. Aqui apenas recordarei o ponto essencial dessas análises. Ter que cuidar das coisas é uma tarefa típica da ética heideggeriana da segunda fase, não dedutível da moral tradicional nem mesmo do ter-que-ser de Ser e tempo. Em Ser e tempo, cuidar sempre também inclui a ocupação para com as coisas. Mas o aspecto resguardador da ocupação com as coisas não está ainda no primeiro plano. Na fase posterior de Heidegger, contudo, surgirá algo como uma ética do resguardo das coisas, junto e além da ética do estar junto. O salvamento do homem do perigo da técnica, o ter que ser definitório do homem moderno, implica agora também o salvamento da coisa, do ente como tal, como parte do salvamento do homem, mais precisamente da essência do homem.

\section{Referências bibliográficas}

APEL, Karl-Otto. Diskurs und Verantwortung. Frankfurt a/M: Suhrkamp, 1990.

DAHLSTROM, Daniel O. Das logische Vorurteil. Viena: Passagen Verlag, 1994.

GEBERT, Sigbert. Negative Politik. Berlim: Duncker \& Humblot, 1992.

GUIGNON, Charles. Autheticity, moral values, and psychotherapy. In: The Cambridge Companion to Heidegger. Cambridge, 1993.

HEIDEGGER, Martin. Sein und Zeit. Tübingen: Niemeyer, 1927. 1930: Vom Wesen der menschlichen Freiheit, GA, 31. Frankfurt a/M: Klostermann. 1935: Schellings Abhandlung über das Wesen der menschlichen Freiheit (1809). Tübingen:
Niemeyer.
- 1928/29: Einleitung in die Philosophie, GA (Gesamtausgabe), 27. Frankfurt a/M: Klostermann.

\footnotetext{
- 1946: Der Feldweg, GA, 13. Frankfurt a/M: Klostermann.

- 1959: Unterwegs zur Sprache. Pfullingen: Neske: 1959.

- 1989: Die Grundprobleme der Phänomenologie. GA, 24. Frankfurt a/M: Klostermann.

HODGES, Joanna. Heidegger and Ethics. Londres: Routledge, 1995.

LEVINAS, Emmanuel. Totalité et infini. Haia: Nijhoff, 1971.
}
- 1988/1923/: Ontologie (Hermeneutik der Faktizität), GA, 63. Frankfurt a/M: Klostermann. 
LOPARIC, Zeljko. A fenomenologia do agir en Sein und Zeit, Manuscrito, v. 6. n. 2, 1982, p. 149-180.

- Heidegger réu. Campinas: Papirus, 1990.

- Ética e finitude. São Paulo: Educ, 1995.

- Heidegger e a pergunta pela técnica. Cadernos de História de Filosofia da Ciência, Série 3, v.

6, n. 2, 1996, p. 107-138.

. É dizivel o inconsciente? Colóquio Winnicott, PUCSP, 05-07/06/98, 1998a. (manuscrito).

. O fato da razão. Congresso ANPOF, 1998, 1998b (manuscrito).

O ter-que-ser e a praxis racionalizada. 1998c. (manuscrito).

. Etica e finitude, e outros ensaios. São Paulo: Educ, 1999.

MOYSE, Danielle. La morale boulversée: la question de l'éthique chez Martin Heidegger. Heidegger Studies, v. 8, p. 103-121, 1992.

TUGENDHAT, Emst. Selbstbewusstsein und Selbstbestimmung. Frankfurt a/M: Suhrkamp, 1979.

- Vorlesungen über Ethik. Frankfurt a/M: Suhrkamp, 1993.

WINNICOTT, Donald W. Playing and reality. Londres: Penguin Books, 1971.

. Human nature. Londres: Free Association Books, 1988. 